\title{
Clinical Epidemiology of Fractures in Dogs: A Retrospective Study
}

\author{
P. M. Usadadiya, R. H. Bhatt ${ }^{*}$, A. R. Bhadaniya, V. D. Dodia and K. S. Gameti \\ Department of Veterinary Surgery \& Radiology, College of Veterinary Science \& A. H., \\ Junagadh Agricultural University, Junagadh, India \\ *Corresponding author
}

\section{A B S T R A C T}

\begin{tabular}{|l|}
\hline Keyw ord s \\
Fractures in dogs, \\
Clinical \\
epidemiology
\end{tabular}

The present study was carried out to determine the clinical epidemiology of bone fracture in dogs based on three years data of Veterinary Clinical Complex, College of Veterinary Science \& A. H., Junagadh Agricultural University, Junagadh, Gujarat. During study, signalment and clinical details of three years (April, 2017 - March, 2020) cases were analyzed that revealed a total number of 9556 dogs presented for various ailments, in which 2289 (23.95\%) cases were of surgical affections. Out of these, $275(12.01 \%)$ cases were of orthopaedic affections. During the study period, higher incidence of fracture was seen in femur followed by tibia-fibula, radius-ulna and humerus. Dogs in the age group of 1-6 months showed highest occurrence in comparison to other age group. Breed wise incidences of fracture was higher in non-descript breed followed by German shepherd, Labrador, Spitz and others while sex wise male was more affected then female. In this study, incidence of right hindlimb fracture was found higher followed by fracture of left hindlimb, right forelimb and left forelimb.

\section{Introduction}

Long bones are subjected to physiological and non-physiological forces such as automobile accidents, gunshot injuries and falls. Most common causes of fractures are strong forces like bending, compression, shearing and torsional forces. These forces can be transmitted to bone directly and may exceed the ultimate strength of bone, causing a fracture (Jain et al., 2018). Physiological forces transmitted to the bone through the joint surfaces and muscle contraction when exceed the ultimate strength of bone, responsible for fracture. Dogs constitute the majority of domestic pet population. These pets are prone to appendicular bone fractures, which are frequently caused by traumatic injuries or bone pathology (Jani et al., 2014).

\section{Materials and Methods}

To know clinical epidemiology of orthopaedic ailments in dogs, signalment and case details were summarised based on retrospective data of last three years (April-2017 to March2020) from Veterinary Clinical Complex, College of Veterinary Science \& A. H., Junagadh Agricultural University, Junagadh, Gujarat in which signalment was comprised of data regarding age, sex and breed while 
clinical details of cases were furnished with details of limb involvement and diagnosis.

\section{Results and Discussion}

During last three years (April, 2017 - March, 2020), total 9556 cases of dogs were reported at Veterinary Clinical Complex, College of Veterinary Science \& A. H., Junagadh Agricultural University, Junagadh, Gujarat. Out of these, $2289(23.95 \%)$ cases were affected with different types of surgical affections in which 275 (12.01\%) orthopaedic affections were recorded. Similarly, Ali (2013) carried out retrospective study of incidence, occurrence, classification and outcome of small animal fractures during the period of five years (2003-2005). During that period of time, 650 cases were presented in small animal surgery unit. Out of which of 116 (dogs and cats) were presented with history of fractures of different bones. A total of $17.8 \%(116 / 650)$ cases were of fractures in which dogs constituted $13.53 \% \quad(88 / 650)$ while cats were $4.30 \%$ (28/650).

During last three years, highest incidence was recorded in age group of less than 0.5 year(109 cases, 39.63\%), followed by $0.5-1$ year (62 cases, $22.54 \%$ ), 1-2 years (37 cases, $13.45 \%$ ), 2-3 years (22 cases, 8\%), 3-4 years
(22 cases, 8\%), 4-5 years (08 cases, $2.90 \%$ ), 6-10 years (14 cases, $5.09 \%)$ and 10-12 years (1 case, $0.36 \%$ ) as shown in table 1 . Similarly, Jain et al., (2018) reported highest occurrence of fracture in dogs falling in the age group of 1-6 months (49.71\%) followed by $7-12$ months $(20.11 \%), 4-5$ years $(10.65 \%)$, 1-2 years $(7.69 \%)$, 6-7 years (7.10\%), 3-4 years $(3.55 \%)$ and $10-12$ years $(1.18 \%)$. This might be due to the fact that the young ones are more active and not able to cope with hazards unlike their older counterparts. Further, cortices of young dogs are comparatively thinner than the adult, so could not resist even minor trauma resulting in fracture (Aithal et al., 1999).

Incidence of fracture was found higher in males $(158 / 275,57.45 \%)$ as compare to female $(117 / 275,42.55 \%)$ as shown in table 2. Earlier studies by Gahlod et al., (2004) and Kumar et al., (2007) reported higher incidence of long bone fracture in male than the females and tend to wander more than their female counterparts, thus they are more vulnerable to fractures. Further this could also be due to the fact that people like to have male dog more than female dogs, which might be responsible for more population of male dogs (Jani et al., (2014).

Table.1 Age wise distribution of cases showing fractures in dogs

\begin{tabular}{|l|c|c|c|c|c|c|c|c|}
\hline & \multicolumn{8}{|c|}{ Age groups (Years) } \\
\cline { 2 - 10 } & $\mathbf{5 . 5}$ & $\mathbf{0 . 5 - 1}$ & $\mathbf{1 - 2}$ & $\mathbf{2 - 3}$ & $\mathbf{3 - 4}$ & $\mathbf{4 - 5}$ & $\mathbf{6 - 1 0}$ & $\mathbf{1 0 - 1 2}$ \\
\hline No. of cases & 109 & 62 & 37 & 22 & 22 & 8 & 14 & 1 \\
\hline Percentage (\%) & $39.63 \%$ & $22.54 \%$ & $13.45 \%$ & $8 \%$ & $8 \%$ & $2.90 \%$ & $5.09 \%$ & $0.36 \%$ \\
\hline
\end{tabular}

Table.2 Sex wise distribution of cases showing fracture in dogs

\begin{tabular}{|l|c|c|}
\hline & Male & Female \\
\hline No. of cases & 158 & 117 \\
\hline Percentage (\%) & 57.45 & 42.55 \\
\hline
\end{tabular}


Table.3 Distribution of cases showing fracture as per limb involvement in dogs

\begin{tabular}{|l|c|c|c|c|c|c|c|}
\hline & RH & LH & RF & LF & Mandible & Vertebrae & Skull \\
\hline No. of cases & 87 & 82 & 52 & 33 & 13 & 7 & 1 \\
\hline Percentage (\%) & 31.63 & 29.81 & 18.9 & 12 & 4.72 & 2.74 & 0.36 \\
\hline
\end{tabular}

Table.4 Distribution of cases showing fracture as per bone involvement in dogs

\begin{tabular}{|c|c|c|c|c|c|}
\hline Sr. No. & Bone & Percentage (\%) & Sr. No. & Bone & Percentage (\%) \\
\hline $\mathbf{1 .}$ & Femur & $33.81 \%$ & 7. & Metacarpus & $4 \%$ \\
\hline $\mathbf{2 .}$ & Tibia & $18.18 \%$ & 8. & Vertebrae & $2.54 \%$ \\
\hline $\mathbf{3 .}$ & Radius & $13.81 \%$ & 9. & Metatarsal & $0.72 \%$ \\
\hline $\mathbf{4 .}$ & Humerus & $12.72 \%$ & 10. & Skull & $0.36 \%$ \\
\hline $\mathbf{5 .}$ & Hip & $8.72 \%$ & 11. & Scapula & $0.36 \%$ \\
\hline $\mathbf{6 .}$ & Mandible & $4.72 \%$ & & & \\
\hline
\end{tabular}

Breed wise, Non-descript breed showed the highest incidence $(142 / 275,51.63 \%)$ followed by German shepherd $(54 / 275,20 \%)$, Labrador retriever $(29 / 275,10.54 \%)$, Pomeranian/Spitz (17/275, 6.18\%), Doberman (16/275, 5.81\%), Great Dane $(5 / 275,1.81 \%)$, Saint Bernad (5/275, 1.81\%), Rottweiler (4/275, 1.45\%), Golden retriever $(1 / 275,0.36 \%)$, Beagle $(1 / 275,0.36 \%)$ and Lhasa Apso (1/275, $0.36 \%)$. Similar results were observed by Jain et al., (2018) and Sran et al., (2016)who reported highest occurrence of fracture in non-descript dogs $(27.81 \%)$ followed by Labrador (21.89\%), German shepherd (21.30\%), Pomeranian/Spitz (20.11\%), Doberman (3.55\%), Great Dane (2.36\%), St. Bernard (0.59\%), Rottweiler (0.59\%), Mastiff $(0.59 \%)$ and Dalmatian (0.59\%). In the present study, higher incidence in nondescript dogs might be due to higher population and free living nature of these dogs making them more prone to automobile accidents (Borges et al., 2016).

In present study, clinical details of cases were also analyzed that revealed higher occurrence of right hindlimb fracture $(87 / 275,31.63 \%)$ followed by left hindlimb fracture $(82 / 275$, $29.81 \%$ ), right forelimb fracture $(52 / 275$, $18.90 \%)$, left forelimb fracture $(33 / 275,12 \%)$, mandible $(13 / 275,4.72 \%)$, vertebrae $(7 / 275$, $2.74)$ and skull $(1 / 275,0.36 \%)$ as shown in table 3. Moreover, right limb fracture $(139 / 275,50.54 \%)$ was more recorded than the left limb fracture $(115 / 275,41.81 \%)$. Similar results were observed by Jain et al., (2018) in which right hindlimb fracture $(50.00 \%)$ was more observed followed by left hindlimb (38.88\%), left forelimb (5.55\%) and right forelimb (5.55\%).

On the basis of bone involvement, occurrence of fracture was found higher in femur $(93 / 275,33.81 \%)$ followed by fracture of tibia-fibula $(50 / 275,18.18 \%)$, radius-ulna $(38 / 275,13.81 \%)$, humerus $(35 / 275,12.72 \%)$, hip $(24 / 275,8.72 \%)$, mandible $(13 / 275$, $4.72 \%)$, metacarpus $(11 / 275,4 \%)$, vertebrae $(7 / 275,2.54 \%)$, metatarsal $(2 / 275,0.72 \%)$, skull $(1 / 275,0.36 \%)$ and scapula $(1 / 275$, $0.36 \%$ ) as shown in table 4 . Earlier study by Abd El Raouf et al., (2019) reported higher incidence of femur fracture (27.13\%) followed by tibia-fibula (15.5\%), radius-ulna $(11.63 \%)$ and humerus (10.08\%). The percentage of metacarpus or digit fractures was $6.98 \%$ while of metatarsus or digit was $5.43 \%$. This observation indicates that the presence of abundant muscle do not protect the femur from getting fractured (Markel et 
al., 1994). In automobile accidents, animals are likely to be hit from behind, as the animals were slow to react from their hind quarters, might be the cause of more fracture in hindlimb (Harasan, 2003).

In conclusions the clinical epidemiology of fracture in dogs revealed higher incidence in males as compared to females; Age wise young animals are more prone and Nondescript breed is commonly affected. While clinical details show higher incidences of femur fracture and unilateral right side limb involvement in dogs.

\section{References}

Abd El Raouf, M., Ezzeldein, S. A. and Eisa, E. F. M. 2019. Bone fractures in dogs: A retrospective study of 129 dogs. Iraqi J. Vet. Sci., 33(2): 401-405.

Aithal, H.P., Signh, G. R. and Bisht, G. S. 1999Fractures in dogs. A survey of 402 cases Ind. J. Vet. Surg., 20(1): 1521.

Ali, L. B. 2013. Incidence, occurrence, classification and outcome of small animal fractures: a retrospective study (2005-2010). World Acad. Sci. Eng. Technol. 7(3): 191-196.

Borges, C., Rahal, S., Agostinho, F., Mamprim, M., Santos, R., Silva F. E., Carolina M. A. and Monteiro, F. O. 2016. Long bone fracture in cat. A retrospective study. Vet.
Zootec.23(6):504-509.

Gahlod, B. M., Dhakate, M. S., Patil, S. N., Gawande, P. S. and Kamble, M. V. 2004 Retrospective study of fractures in canines - A report of 109 cases. Ind. J. Vet. Surg., 25(2): 122-142.

Harasen, G. 2003 Common long bone fractures in small animal practice part1.Can. Vet. J. 44(4): 333-334.

Jain, R., Shukla, B. P., Nema, S., Shukla, S., Chabra, D. and Karmore, S. K. 2018. Incidence of fracture in dog: a retrospective study. Vet. Pract., 19(1): 63-65.

Jani, S. M. Y., Kushwaha, R. B., Gupta, A. K., Malik, K. and Soodan, J. S. 2014 Occurrence of fractures in dogs: A retrospective study of five years. Indian J. Vet. Surg., 35(1): 73-74.

Kumar, K., Moghal, I. V., Aithal, H. P., Kinjavdekar, P., Amarpal Singh, G. R., Pawde, M. and Kushwaha, R. B. 2007. Occurrence and pattern of long bone fractures in growing dogs with normal and osteopenic bones. J. Vet. Med. Series-A 54(9): 484-490.

Markel, M. D., Sielman, E.,Rapoff, A. J. and Kohles, S. S. 1994. Mechanical properties of long bones in dogs. Am. J.Vet. Res. 55(8): 1178-1183.

Sran, T. K., Singh, S. S., Mohindroo, J. and Saini, N. S. 2016. Frequency of long bone fractures in dogs: A retrospective study. Indian J. Vet. Surg., 37(1): 1-5.

\section{How to cite this article:}

Usadadiya, P. M., R. H. Bhatt, A. R. Bhadaniya, V. D. Dodia and Gameti, K. S. 2020. Clinical Epidemiology of Fractures in Dogs: A Retrospective Study. Int.J.Curr.Microbiol.App.Sci. 9(09): 1097-1100. doi: https://doi.org/10.20546/ijcmas.2020.909.137 